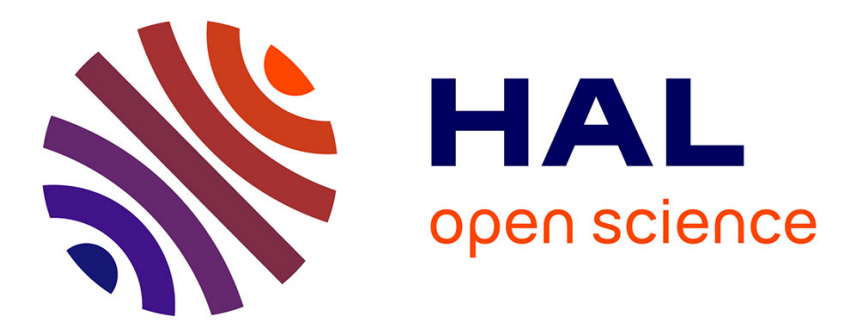

\title{
Computation of signatures of coherent systems with five components
}

\author{
Jorge Navarro, Rafael Rubio
}

\section{To cite this version:}

Jorge Navarro, Rafael Rubio. Computation of signatures of coherent systems with five components. Communications in Statistics - Simulation and Computation, 2009, 39 (01), pp.68-84. 10.1080/03610910903312185 . hal-00537681

\section{HAL Id: hal-00537681 \\ https://hal.science/hal-00537681}

Submitted on 19 Nov 2010

HAL is a multi-disciplinary open access archive for the deposit and dissemination of scientific research documents, whether they are published or not. The documents may come from teaching and research institutions in France or abroad, or from public or private research centers.
L'archive ouverte pluridisciplinaire HAL, est destinée au dépôt et à la diffusion de documents scientifiques de niveau recherche, publiés ou non, émanant des établissements d'enseignement et de recherche français ou étrangers, des laboratoires publics ou privés. 


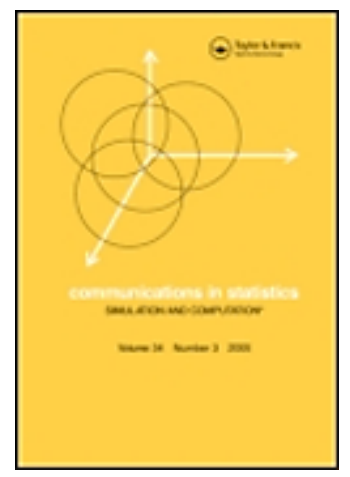

\section{Computation of signatures of coherent systems with five components}

\begin{tabular}{|c|c|}
\hline Journal: & Communications in Statistics - Simulation and Computation \\
\hline Manuscript ID: & LSSP-2008-0261.R2 \\
\hline Manuscript Type: & Original Paper \\
\hline $\begin{array}{r}\text { Date Submitted by the } \\
\text { Author: }\end{array}$ & 06-Jul-2009 \\
\hline Complete List of Authors: & $\begin{array}{l}\text { Navarro, Jorge; Universidad de Murcia, Estadistica e I.O. } \\
\text { Rubio, Rafael; Universidad de Murcia }\end{array}$ \\
\hline Keywords: & $\begin{array}{l}\text { coherent systems, reliability, signature, minimal signature, } \\
\text { exponential distribution }\end{array}$ \\
\hline Abstract: & $\begin{array}{l}\text { The signatures of coherent systems are useful tools to compute the } \\
\text { system reliability functions, the system expected lifetimes and to } \\
\text { compare different systems using stochastic orderings. It is well } \\
\text { known that there exist } 2,5 \text { and } 20 \text { different coherent systems with } \\
2,3 \text { and } 4 \text { components, respectively. In this paper, we obtain an } \\
\text { algorithm to compute all the coherent systems with n components } \\
\text { and their signatures. } \\
\text { Using this algorithm we show that there exist } 180 \text { coherent systems } \\
\text { with } 5 \text { components and we compute their signatures. }\end{array}$ \\
\hline \multicolumn{2}{|c|}{$\begin{array}{l}\text { Note: The following files were submitted by the author for peer review, but cannot be converted } \\
\text { to PDF. You must view these files (e.g. movies) online. }\end{array}$} \\
\hline Navarro-Rubio2008R1-sent & \\
\hline
\end{tabular}




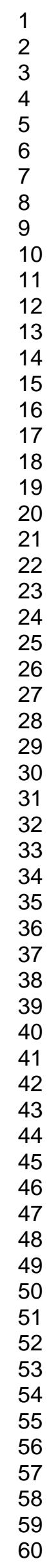

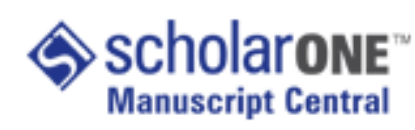
7 


\section{RELIABILITY THEORY}

COMPUTATIONS OF SIGNATURES OF COHERENT SYSTEMS WITH FIVE COMPONENTS

Jorge Navarro ${ }^{1}$ and Rafael Rubio

Facultad de Matematicas

Universidad de Murcia

30100 Murcia, Spain

jorgenav@um.es

Key Words: coherent systems; reliability; signature; minimal signature; exponential distribution.

\section{ABSTRACT}

The signatures of coherent systems are useful tools to compute the system reliability functions, the system expected lifetimes and to compare different systems using stochastic orderings. It is well known that there exist 2, 5 and 20 different coherent systems with 2, 3 and 4 components, respectively. The signatures for these systems were given in Shaked and Suarez-Llorens (2003, JASA 98, 693-702). In this paper, we obtain an algorithm to compute all the coherent systems with $n$ components and their signatures. Using this algorithm we show that there exist 180 coherent systems with 5 components and we compute their signatures.

\section{INTRODUCTION}

The study of coherent systems is a very relevant topic in reliability and survival studies. The concept of signature of a coherent system, introduced by Samaniego (1985), has become a very useful tool to compute the system reliability and expected lifetime and to compare different systems using stochastic orderings when the components are independent and iden-

\footnotetext{
${ }^{1}$ Partially Supported by Ministerio de Ciencia y Tecnología under grant MTM2006-12834
} 
tically distributed (IID) with a common continuous distribution. An excellent review of the results based on signatures obtained since 1985 was given in Samaniego (2007). Additional results for systems with IID or exchangeable components can be seen in Navarro and Rychlik (2007), Navarro, Rychlik and Shaked (2007), Bairamov and Arnold (2008), Bhattacharya and Samaniego (2008), Li and Zhang (2008), Navarro, Balakrishnan and Samaniego (2008) and Navarro, Samaniego, Balakrishnan and Bhattacharya (2008).

Recently, Navarro, Ruiz and Sandoval (2007) introduced the concepts of minimal and maximal signatures of coherent systems with exchangeable components. These signatures are also useful in order to study coherent systems. Some applications can be seen in Navarro and Shaked (2006), Navarro, Ruiz and Sandoval (2007), Navarro and Eryilmaz (2007), Navarro and Hernandez (2008) and Eryilmaz (2008).

It is well known that there exist only two coherent systems with two components, the series and the parallel systems. Shaked and Suarez-Llorens (2003) proved that there exist 5 and 20 different coherent systems with 3 and 4 exchangeable components, respectively. They also computed the signatures of these systems and they used them to obtain some ordering properties. The signatures were also used in Kochar, Mukerjee, and Samaniego (1999), Navarro, Ruiz and Sandoval (2005) and Navarro, Samaniego, Balakrishnan and Bhattacharya (2008) to study system comparisons based on stochastic, hazard rate and likelihood ratio orderings. The number of coherent system increases exponentially as the number of components increases (Samaniego 2007, p. 11).

In this paper, we introduce an algorithm to compute coherent systems and we use it to obtain all the different coherent system with 5 components and computing their signatures, minimal signatures and maximal signatures. Moreover, we compute their expected lifetimes (also called in reliability studies Mean Time To Failure, MTTF) when the components are IID with a common exponential distribution. These expected values are used to order the systems given in Table 1 from the worse one (series system) to the best one (parallel system).

The remainder of this paper is organized as follows. In Section 2, we give the basic concepts and the main result of the paper, an algorithm to generate all the coherent sys- 
tems with $n$ components. In Section 3, we use this algorithm to compute all the coherent systems with five components, their signatures and their expected lifetimes in the case of IID component lifetimes with a common exponential distribution. In Section 4, we discuss the advantages and disadvantages of the results included in this paper, discussing some open questions and topics for future research. The tables are given in the Appendix.

\section{THE MAIN RESULT}

Let us consider a system $\psi$ with $n$ components which has two possible states, $\psi=1$ if the system is functioning and $\psi=0$ if the system has failed. We assume that the state of the system is determined completely by the states of the components, so that we may write

$$
\psi=\psi\left(x_{1}, x_{2}, \ldots, x_{n}\right)
$$

where $x_{i}=1$ if the $i$ th component is functioning and $x_{i}=0$ if it has failed. The function $\psi$ is called the structure function. A system $\psi$ is a coherent system (Barlow and Proschan 1975, p. 6) if $\psi$ is non-decreasing in every component and for every $i=1,2, \ldots, n, \psi$ is strictly increasing in $x_{i}$ for some specific values of $x_{1}, x_{2}, \ldots, x_{i-1}, x_{i+1}, \ldots, x_{n}$. The first property means that if a system is working and we replace a failed component by a functioning component, then the system must be working. The second property says that every component is relevant for the system in some situations, that is, for each $i$ there exists $\mathbf{x}=\left(x_{1}, x_{2}, \ldots, x_{n}\right) \in\{0,1\}^{n}$ such that the system works $\left(i . e . \psi\left(x_{1}, x_{2}, \ldots, x_{n}\right)=1\right)$ if and only if $x_{i}=1$. The dual system of a coherent system with structure function $\psi$ is the system with structure function

$$
\psi_{D}\left(x_{1}, x_{2}, \ldots, x_{n}\right)=1-\psi\left(1-x_{1}, 1-x_{2}, \ldots, 1-x_{n}\right)
$$

A path set for a given system $\psi$ is a set of indices $P$ such that if the components in $P$ work, then the system works. A path set $P$ is a minimal path set if no proper subset of $P$ is a path set. For example, the minimal path sets of the system with structure function $\psi\left(x_{1}, x_{2}, x_{3}\right)=\min \left(x_{1}, \max \left(x_{2}, x_{3}\right)\right)$ are $P_{1}=\{1,2\}$ and $P_{2}=\{1,3\}$. The structure function 
of a coherent system can be written in terms of its minimal path sets as

$$
\psi\left(x_{1}, x_{2}, \ldots, x_{n}\right)=\max _{1 \leq j \leq m} \min _{i \in P_{j}} x_{i}
$$

where the sets $P_{1}, P_{2}, \ldots, P_{m}$ are all the minimal path sets of the system. A proof of (1) may be found in Barlow and Proschan (1975, p. 12).

The next well known lemma characterizes the minimal path sets of a coherent system (see Exercise 5, Barlow and Proschan, 1975, p. 15). Hence the minimal path sets can be used to obtain all the coherent systems with $n$ components.

Lemma 1. If $P_{1}, P_{2}, \ldots, P_{m}$ are subsets of $\{1,2, \ldots, n\}$, then they are the minimal path sets of a coherent system with $n$ components if, and only if, $P_{i} \nsubseteq P_{j}$ for all $i \neq j$ and

$$
P_{1} \cup P_{2} \cup \ldots \cup P_{m}=\{1,2, \ldots, n\} .
$$

The lifetime $T$ of a coherent system with structure function $\psi$ and component lifetimes $X_{1}, X_{2}, \ldots, X_{n}$ can be written as

$$
T=\psi\left(X_{1}, X_{2}, \ldots, X_{n}\right)=\max _{1 \leq j \leq m} \min _{i \in P_{j}} X_{i}
$$

A proof of (2) may be found in Barlow and Proschan (1975, p. 12). It is easy to prove from (2) using the inclusion-exclusion formula that the reliability function $\bar{F}_{T}(t)=\operatorname{Pr}(T>t)$ of $T$ can be written as

$$
\bar{F}_{T}(t)=\sum_{1 \leq j \leq m} \bar{F}_{P_{j}}(t)-\sum_{1 \leq i<j \leq m} \bar{F}_{P_{i} \cup P_{j}}(t)+\ldots+(-1)^{m+1} \bar{F}_{P_{1} \cup P_{2} \cup \ldots \cup P_{m}}(t),
$$

where $\bar{F}_{P}(t)=\operatorname{Pr}\left(\min _{i \in P} X_{i}>t\right)$ is the reliability function of the lifetime of the series system with components in $P$.

Samaniego (1985) defined the signature vector of a coherent system as $\mathbf{s}=\left(s_{1}, s_{2}, \ldots, s_{n}\right)$, where $s_{i}=\operatorname{Pr}\left(T=X_{i: n}\right)$ for $i=1,2, \ldots, n$ and $X_{1: n}, X_{2: n}, \ldots, X_{n: n}$ are the order statistics associated to the component lifetimes $X_{1}, X_{2}, \ldots, X_{n}$. He proved that if the component lifetimes are IID with a common continuous distribution, then s only depends on the structure function of the system and the reliability function $\bar{F}_{T}(t)=\operatorname{Pr}(T>t)$ of $T$ can be written as

$$
\bar{F}_{T}(t)=\sum_{i=1}^{n} s_{i} \bar{F}_{i: n}(t)
$$


where $\bar{F}_{i: n}(t)=\operatorname{Pr}\left(X_{i: n}>t\right)$ for $i=1,2, \ldots, n$. Navarro and Rychlik (2007) proved that this representation also holds for coherent systems with component lifetimes having a joint exchangeable absolutely continuous distribution, that is, when $\left(X_{1}, X_{2}, \ldots, X_{n}\right)$ has a joint probability density function $f$ such that

$$
f\left(x_{1}, x_{2}, \ldots, x_{n}\right)=f\left(x_{\sigma(1)}, x_{\sigma(2)}, \ldots, x_{\sigma(n)}\right)
$$

for any permutation $\sigma$. Kochar, Mukerjee and Samaniego (1999) proved that if a system $\psi$ has signature $\mathbf{s}=\left(s_{1}, s_{2}, \ldots, s_{n}\right)$, then the signature of the dual system $\psi_{D}$ is

$$
\mathbf{s}_{D}=\left(s_{n}, s_{n-1}, \ldots, s_{1}\right)
$$

Recently, Navarro, Samaniego, Balakrishnan and Bhattacharya (2008) proved that representation (4) also holds for systems with exchangeable components without the assumption of an absolutely continuous joint distribution but, in this case, one must use the signature vector obtained in the absolutely continuous case. Moreover, they showed that if $T=\psi\left(X_{1}, X_{2}, \ldots, X_{k}\right)$ is the lifetime of a coherent system with $k$ components and $k<n$, then there exists a vector of coefficients $\left(s_{1}, s_{2}, \ldots, s_{n}\right)$ such that (4) holds. This vector was called signature of order $n$. They compute the signatures of order 4 for all the coherent systems with 4 or fewer components and compare them stochastically.

Navarro, Ruiz and Sandoval (2007) proved that the reliability function $\bar{F}_{T}$ of a coherent system with exchangeable components can also be written as

$$
\bar{F}_{T}(t)=\sum_{i=1}^{n} a_{i} \bar{F}_{1: i}(t)=\sum_{i=1}^{n} b_{i} \bar{F}_{i: i}(t),
$$

where $\bar{F}_{1: i}(t)=\operatorname{Pr}\left(X_{1: i}>t\right)$ and $\bar{F}_{i: i}(t)=\operatorname{Pr}\left(X_{i: i}>t\right)$ for $i=1,2, \ldots, n$, that is, they are the reliability functions of series and parallel system lifetimes, respectively. The vectors of coefficients $\mathbf{a}=\left(a_{1}, a_{2}, \ldots, a_{n}\right)$ and $\mathbf{b}=\left(b_{1}, b_{2}, \ldots, b_{n}\right)$ (which only depend on the structure function of the system) were called minimal signature and maximal signature, respectively. They also proved that the coefficients in a can be obtained from representation (3). Moreover, they showed that the minimal (maximal) signature of the dual system is equal to the maximal 
(minimal) signature of the parent one, that is,

$$
\mathbf{a}_{D}=\mathbf{b} \text { and } \mathbf{b}_{D}=\mathbf{a} \text {. }
$$

From (3) or from the expressions given in David and Nagaraja (2003, p. 46), we have that there exist two triangular (non-singular) matrices $A_{n}$ and $B_{n}$ such that

$$
\mathbf{s}=\mathbf{a} A_{n}=\mathbf{b} B_{n}
$$

Therefore, if we know a signature vector (i.e. we know s, a or b) we can compute the other two vectors.

The aim of the following algorithm is to compute all the coherent systems with $n$ components using the minimal path sets representation (2) and Lemma 1 . We use a recurrence method in the number $m$ of minimal path sets. Moreover, we include a method to delete collections of minimal path sets which lead to the same coherent systems. For example the minimal path sets $P_{1}=\{1,2\}, P_{2}=\{1,3\}$ determine the same coherent system as the minimal path sets $P_{1}=\{1,2\}, P_{2}=\{2,3\}$. Even in the non-exchangeable case, note that the lifetime $T_{2}$ of the system determined by the minimal path sets $P_{1}=\{1,2\}, P_{2}=\{2,3\}$, $T_{2}=\psi_{2}\left(X_{1}, X_{2}, X_{3}\right)=\min \left(X_{2}, \min \left(X_{1}, X_{3}\right)\right)$, can be obtained using the structure function $\psi_{1}\left(x_{1}, x_{2}, x_{3}\right)=\min \left(x_{1}, \min \left(x_{2}, x_{3}\right)\right)$ determined by the minimal path sets $P_{1}=\{1,2\}, P_{2}=$ $\{1,3\}$ by permuting the component lifetimes in the random vector of component lifetimes, that is, $T_{2}=\psi_{1}\left(X_{2}, X_{1}, X_{3}\right)$. So we say $P_{1}=\{1,2\}, P_{2}=\{1,3\}$ and $P_{1}=\{1,2\}, P_{2}=\{2,3\}$ determine the same system.

ALGORITHM. Generation of coherent systems with $n$ components.

STEP 1. For $m=1$ ( $m$ is the number of minimal path sets), the unique coherent system is the series system with minimal path set $P_{1}=\{1,2, \ldots, n\}$.

STEP 2. For $m=2$, we generate the coherent systems by combining all the pairs of subsets obtained from $\{1,2, \ldots, n\}$ and deleting the combinations which do not determine coherent systems (i.e. which do not satisfy the properties given in Lemma 1) or that which 
determine coherent systems already determined by a preceding combination. We save all these combinations $\left\{P_{1}, P_{2}\right\}$ in an increasing cardinality order (i.e. $\left|P_{1}\right| \leq\left|P_{2}\right|$ ).

STEP 3. For $m=3,4, \ldots$, we generate the coherent systems recursively in $m$ as follows. If $\left\{P_{1}, P_{2}, \ldots, P_{m-1}\right\}$ belongs to the list of sets of $m-1$ minimal path sets which determine coherent systems, we combine $P_{1}, P_{2}, \ldots, P_{m-2}$ with all the pairs of non-empty subsets obtained from $\{1,2, \ldots, n\}$. We delete the collections of minimal path sets which do not determine coherent systems or that which determine coherent systems already determined by a preceding combination. We save the list of these collections of minimal path sets $\left\{P_{1}, P_{2}, \ldots, P_{m}\right\}$ in an increasing cardinality order (i.e. with $\left.\left|P_{1}\right| \leq\left|P_{2}\right| \leq \ldots \leq\left|P_{m}\right|\right)$.

STEP 4. Stop when for $m$ the list of new coherent systems is empty.

Theorem 2. The preceding algorithm generates all the coherent systems with $n$ components. Proof. The combinations generated by Algorithm 1 determine coherent systems since they satisfy the properties of Lemma 1.

Consider a coherent system $\psi$ with minimal path sets $P_{1}, P_{2}, \ldots, P_{m}$. Let us see that $\psi$ is equal to a coherent system generated by the preceding algorithm. Without loss of generality we can assume that $\left|P_{1}\right| \leq\left|P_{2}\right| \leq \ldots \leq\left|P_{m}\right|$. If $m=1$ or $m=2$, then the property is true because the algorithm generates all the options.

By induction on $m$, suppose that the property is true for $m-1$, that is, let us assume that the algorithm generates all the coherent systems with $m-1$ minimal path sets. Then, for a given collection of $m$ minimal path sets $P_{1}, P_{2}, \ldots, P_{m}$ which determine a coherent system, we have two options:

(i) If $\cup_{i=1}^{m-1} P_{i}=\{1,2, \ldots, n\}$, then $\left\{P_{1}, P_{2}, \ldots, P_{m-1}\right\}$ are the minimal path sets of a coherent system $\psi^{*}$ with $m-1$ minimal path sets. So, by induction, $\psi^{*}$ is obtained in the step $m-1$. Therefore, $\psi$ is obtained when we add the pair $\left\{P_{m-1}, P_{m}\right\}$ to $\left\{P_{1}, P_{2}, \ldots, P_{m-2}\right\}$.

(ii) If $\cup_{i=1}^{m-1} P_{i} \neq\{1,2, \ldots, n\}$, then $\left\{P_{1}, P_{2}, \ldots, P_{m-1}\right\}$ does not determine a coherent system. Define

$$
Q=P_{m-1} \cup\left(\{1,2, \ldots, n\}-\cup_{i=1}^{m-2} P_{i}\right) .
$$


Then the collection $\left\{P_{1}, P_{2}, \ldots, P_{m-2}, Q\right\}$ satisfies $P_{1} \cup P_{2} \cup \cdots \cup P_{m-2} \cup Q=\{1,2, \ldots, n\}$, $P_{i} \nsubseteq Q$ and $Q \nsubseteq P_{i}$ (since $P_{i} \nsubseteq P_{m-1}$ and $P_{m-1} \nsubseteq P_{i}$ ) for $i=1,2, \ldots, m-2$. Then, from Lemma 1, it determines a coherent system. By induction, as the system determined by $\left\{P_{1}, P_{2}, \ldots, P_{m-2}, Q\right\}$ has $m-1$ minimal path sets, it is generated by the algorithm in step $m-1$. Moreover, as $\left|P_{m-2}\right| \leq\left|P_{m-1}\right|<|Q|, Q$ is the last minimal path set in the collection. Therefore, $\psi$ is obtained in step $m$ of the algorithm when we delete $Q$ in the collection $\left\{P_{1}, P_{2}, \ldots, P_{m-2}, Q\right\}$ and we add the pair $\left\{P_{m-1}, P_{m}\right\}$.

The main advantage of the preceding algorithm is that it is faster than an exhaustive enumeration of all the options of $m$ subsets from $\{1,2, \ldots, n\}$ for $m=1,2, \ldots$. Note that in the algorithm we only need all the pairs of subsets from $\{1,2, \ldots, n\}$. This list is computed in Step 2 for $m=2$ and it is used several times in Step 3 for $m=3,4, \ldots$. This advantage allows us to compute all the coherent systems with 5 components (see next section) using a standard PC while this is not possible using an exhaustive enumeration method. Even more, we have computed all the coherent systems with 6 components. There are 180 and 16145 coherent systems with 5 and 6 components, respectively. The coherent systems with 5 components are given in Table 1 . A file with the coherent systems with 6 components can be obtained from the authors. However, we must note that the number of coherent systems with $n$ components grows faster than an exponential function of $n$ and hence our algorithm cannot be computed in a short time for any $n$.

Moreover, the algorithm provides the minimal path sets of the systems. Hence we can compute easily their minimal signatures using (3). Therefore we can compute Samaniego signatures $\mathbf{s}$ and maximal signatures $\mathbf{b}$ using (8) and

$$
\mathbf{b}=\mathbf{a} A_{n} B_{n}^{-1}
$$

These signatures can be used to compute system reliability functions and moments when the component lifetimes have a specific distribution. This procedure is illustrated in the next section for systems with 5 exchangeable components. They can also be used to obtain 
stochastic ordering properties using the results given in Kochar, Mukerjee and Samaniego (1999) and Navarro, Ruiz and Sandoval (2005).

\section{COHERENT SYSTEMS WITH 5 COMPONENTS}

We have written a code to compute all the coherent systems with 5 components using the algorithm given in the preceding section. Moreover, we have computed their signatures. It is not clear how the systems can be ordered. Hence, we have computed their expected lifetimes assuming that the component lifetimes are IID exponentially distributed with common mean $\mu$. To compute these expected lifetimes we use that, if $\bar{F}(t)=\exp (-t / \mu)$ for $t \geq 0$, then $\bar{F}_{1: i}(t)=\exp (-i t / \mu)$ for $t \geq 0$ and $E\left(X_{1: i}\right)=\mu / i$ for $i=1,2, \ldots, n$. Therefore, from (6), the expected lifetime of a system with minimal signature a and IID exponential components is given by

$$
E(T)=\mu \sum_{i=1}^{n} \frac{a_{i}}{i} .
$$

The minimal path sets of the 180 coherent systems with 5 components are given in Table 1. They are ordered using their expected lifetimes in the IID exponential case. Their structure functions and lifetimes can be obtained from (2).

In Table 2 we give the signatures of the 180 coherent systems with 5 components. Note that different systems can have the same signature. For example, systems numbers 9 and 10 have the same signatures. However, they are different system since their minimal path sets are $P_{1}=\{1,2,3\}, P_{2}=\{1,2,4\}$ and $P_{3}=\{1,3,4,5\}$ (system number 9 ) and $P_{1}=\{1,2,3\}$ and $P_{2}=\{1,4,5\}$ (system number 10). Therefore, from the results given in Navarro, Samaniego, Balakrishnan, and Bhattacharya (2008), their lifetimes will be equal in law (distribution) if they have exchangeable components. However, this property is not necessarily true in the case of non-exchangeable components. To obtain the signatures given in Table 2, we first compute the minimal signatures using minimal path set representation (3) 
and then we compute Samaniego's signatures using that

$$
\mathbf{s}=\mathbf{a} A_{5}=\mathbf{a}\left(\begin{array}{ccccc}
\frac{1}{5} & \frac{1}{5} & \frac{1}{5} & \frac{1}{5} & \frac{1}{5} \\
\frac{2}{5} & \frac{3}{10} & \frac{1}{5} & \frac{1}{10} & 0 \\
\frac{3}{5} & \frac{3}{10} & \frac{1}{10} & 0 & 0 \\
\frac{4}{5} & \frac{1}{5} & 0 & 0 & 0 \\
1 & 0 & 0 & 0 & 0
\end{array}\right)
$$

We do not include maximal signatures since they can be obtained from properties (5) and (7). For example, the dual of system 81 with signature $\mathbf{s}=(0,3 / 10,1 / 2,1 / 5,0)$ is system 103 with signature $\mathbf{s}_{D}=(0,1 / 5,1 / 2,3 / 10,0)$ and hence, the maximal signature of system 81 is $\mathbf{b}=\mathbf{a}_{D}=(0,3,-1,-2,1)$ (i.e. the minimal signature of its dual system) and the maximal signature of system number 103 is $\mathbf{b}_{D}=\mathbf{a}=(0,2,1,-3,1)$. In Table 2 we also include $E(T)$ when the system have IID exponential component lifetimes with common mean $\mu=1$ (if the mean is $\mu$, then $\left.E\left(T_{\mu}\right)=\mu E(T)\right)$.

The minimal signatures of systems with less than 5 components were given in Tables $1 \& 2$ of Navarro, Ruiz and Sandoval (2007) and their expected values in the exponential case were given in Tables $2 \& 3$ of Navarro and Rycklik (2007). Thus, we can compute their signatures of order 5 and compare stochastically systems with 5 or less exchangeable components using the results given in Kochar, Mukerjee, and Samaniego (1999), Navarro, Ruiz and Sandoval (2005) and Navarro, Samaniego, Balakrishnan, and Bhattacharya (2008). In the following example we show how the signatures can be used to compute reliability functions, expected lifetimes and hazard rate functions or to compare stochastically a system with the components on it.

Example 3. The system number 103 in Table 1 has minimal path sets $P_{1}=\{1,2\}, P_{2}=$ $\{1,3\}, P_{3}=\{1,4\}, P_{4}=\{2,3,4\}$ and $P_{5}=\{2,3,5\}$, lifetime

$$
T=\max \left(\min \left(X_{1}, \max \left(X_{2}, X_{3}, X_{4}\right)\right), \min \left(X_{2}, X_{3}, X_{4}\right), \min \left(X_{2}, X_{3}, X_{5}\right)\right)
$$

signature $(0,1 / 5,1 / 2,3 / 10,0)$ and minimal signature $(0,3,-1,-2,1)$. If the components are IID with common reliability function $\bar{F}$ and probability density function $f$, then the reliability 
$\bar{F}_{T}$ and hazard rate $h_{T}=f_{T} / \bar{F}_{T}$ functions of the system can be computed using the minimal signature and (6) through

$$
\bar{F}_{T}(t)=3 \bar{F}^{2}(t)-\bar{F}^{3}(t)-2 \bar{F}^{4}(t)+\bar{F}^{5}(t)
$$

and

$$
h_{T}(t)=f(t) \frac{6-3 \bar{F}(t)-8 \bar{F}^{2}(t)+5 \bar{F}^{3}(t)}{3 \bar{F}(t)-\bar{F}^{2}(t)-2 \bar{F}^{3}(t)+\bar{F}^{4}(t)},
$$

respectively. In particular, if the components are IID exponential with mean 1 , then $E(T)=$ $0.8667, \bar{F}_{T}(t)=3 e^{-2 t}-e^{-3 t}-2 e^{-4 t}+e^{-5 t}$ and

$$
h_{T}(t)=\frac{6-3 e^{-t}-8 e^{-2 t}+5 e^{-3 t}}{3-e^{-t}-2 e^{-2 t}+e^{-3 t}}
$$

for $t \geq 0$. By plotting this expression we see that $h_{T}$ is strictly increasing with $h_{T}(0)=0$ and $\lim _{t \rightarrow \infty} h_{T}(t)=2$, that is, it is asymptotically equivalent to a two component series system (see Navarro and Shaked, 2006). Therefore, as the common hazard rate of the component lifetimes $X_{i}$ is $h(t)=1$, then $X_{i}$ and $T$ are not hazard rate ordered. By plotting $\bar{F}$ and $\bar{F}_{T}$ we see that $X_{i}$ and $T$ are not stochastically ordered. The system is more (less) reliable than its components for $t \in(0,0.8095)$ ( $t>0.8095)$. However, if we compare their expected lifetimes $(M T T F)$, we have $E(T)=0.8667<E(T)=1$.

\section{SUMMARY}

Samaniego (2007, p. 11) noted that the number of coherent systems with $n$ components grows exponentially and that there are more than a billion coherent systems with 30 components. Therefore, finding an efficient algorithm for identifying all the coherent systems of order $n$ is a difficult open problem. However, in this paper we show that some advances can be obtained for small $n$ obtaining an algorithm which allow us to compute all the coherent systems with 5 and 6 components. Moreover, we believe that with some improvements, this algorithm might allow us to compute the systems with 7 (or even 8) components. However, note that even before of the process of deleting duplications of coherent systems, the number of operations in step 3 of our algorithm grows faster than an exponential function of the number $n$ of components. Hence it cannot be computed in a short time for arbitrary $n$. 
The algorithm is based on the minimal path set representation and hence it allows us to compute systems signatures. Therefore we can compute system moments and system reliability functions. This fact allows us to compare systems in the IID case when we know the component reliability function. Moreover, using the results in Kochar, Mukerjee, and Samaniego (1999) and Navarro, Ruiz and Sandoval (2005) we can obtain stochastic ordering properties based on signatures in the IID and exchangeable cases, respectively. Even more, from the results given in Navarro, Samaniego, Balakrishnan, and Bhattacharya (2008), we can compare stochastically systems with different number of components. A complete study of these ordering relations for systems with 5 or less components is left for future research.

\section{ACKNOWLEDGEMENT}

The authors wish to thank the anonymous referee for some comments which led to a significantly improved version of the paper.

\section{BIBLIOGRAPHY}

Barlow, R.E. and Proschan, F. (1975). Statistical Theory of Reliability and Life Testing. Holt, Rinehart and Winston, New York.

Bairamov, I. and Arnold, B.C. (2008). On the residual lifelengths of the remaining components in an $n-k+1$ out of $n$ system. Statist. Probab. Lett. 78, 945-952.

Bhattacharya, D. and Samaniego, F.J. (2008). On the optimal allocation of components within coherent systems. Statist. Probab. Lett. 78, 938-943.

David, H.A. and Nagaraja, H.N. (2003). Order Statistics, Third edition. John Wiley \& Sons, Hoboken, New Kersey.

Eryilmaz, S. (2008). Consecutive $k$-out-of- $n: G$ System in stress-strength setup. Comm. Statist. - Simulation and Computation 37 (3), 579-589.

Kochar, S., Mukerjee, H. and Samaniego, F.J. (1999) The "signature" of a coherent system and its application to comparison among systems. Naval Res. Logist. 46, 507-523. 
Li, X. and Zhang, Z. (2008). Some stochastic comparisons of conditional coherent systems. Appl. Stochastic Models in Business and Industry 24, 541-549.

Navarro, J., Balakrishnan, N. and Samaniego, F.J. (2008). Mixture representations of residual lifetimes of used systems. J. Appl. Probab. 45 (4), 1097-1112.

Navarro, J. and Eryilmaz, S. (2007). Mean residual lifetimes of consecutive $k$-out-of- $n$ systems. J. Appl. Probab. 44 (1), 82-98.

Navarro J. and Hernandez, P.J. (2008). Mean residual life functions of finite mixtures and systems. Metrika 67, 277-298.

Navarro, J., Ruiz, J.M. and Sandoval, C.J. (2005). A note on comparisons among coherent systems with dependent components using signatures. Statist. Probab. Lett. 72, 179-185.

Navarro, J., Ruiz, J.M. and Sandoval, C.J. (2007). Properties of coherent systems with dependent components. Comm. Statist. - Theory Methods 36, 175-191.

Navarro, J. and Rychlik, T. (2007). Reliability and expectation bounds for coherent systems with exchangeable components. J. Multivariate Anal. 98, 102-113.

Navarro, J., Rychlik, T. and Shaked, M. (2007). Are the Order Statistics Ordered? A Survey of Recent Results. Comm. Statist. - Theory Methods 36, 1273-1290.

Navarro, J., Samaniego, F.J., Balakrishnan, N. and Bhattacharya, D. (2008). On the application and extension of system signatures to problems in engineering reliability. Naval Res. Logist. 55, 313-327.

Navarro, J. and Shaked, M. (2006). Hazard Rate Ordering of Order Statistics and Systems. J. Appl. Probab. 43, 391-408.

Samaniego, F. (1985). On closure of the IFR class under formation of coherent systems. IEEE Trans. Reliab. R-34, 69-72. 
Samaniego, F. (2007). System Signatures and their Applications in Engineering Reliability, International Series in Operations Research \& Management Science 110, Springer, New York.

Shaked, M. and Suarez-Llorens, A. (2003). On the comparison of reliability experiments based on the convolution order. J. Amer. Statist. Assoc. 98, 693-702. 


\section{APPENDIX}

Table 1: Coherent systems with 5 components

\begin{tabular}{|l|l|}
\hline $\mathrm{N}$ & Minimal path sets \\
\hline 1 & $P_{1}=\{1,2,3,4,5\}$ \\
\hline 2 & $P_{1}=\{1,2,3,4\}, P_{2}=\{1,2,3,5\}$ \\
\hline 3 & $P_{1}=\{1,2,3,4\}, P_{2}=\{1,2,3,5\}, P_{3}=\{1,2,4,5\}$ \\
\hline 4 & $P_{1}=\{1,2,3\}, P_{2}=\{1,2,4,5\}$ \\
\hline 5 & $P_{1}=\{1,2,3,4\}, P_{2}=\{1,2,3,5\}, P_{3}=\{1,2,4,5\}, P_{4}=\{1,3,4,5\}$ \\
\hline 6 & $P_{1}=\{1,2,3\}, P_{2}=\{1,2,4,5\}, P_{3}=\{1,3,4,5\}$ \\
\hline 7 & $P_{1}=\{1,2,3,4\}, P_{2}=\{1,2,3,5\}, P_{3}=\{1,2,4,5\}, P_{4}=\{1,3,4,5\}, P_{5}=\{2,3,4,5\}$ \\
\hline 8 & $P_{1}=\{1,2,3\}, P_{2}=\{1,2,4\}, P_{3}=\{1,2,5\}$ \\
\hline 9 & $P_{1}=\{1,2,3\}, P_{2}=\{1,2,4\}, P_{3}=\{1,3,4,5\}$ \\
\hline 10 & $P_{1}=\{1,2,3\}, P_{2}=\{1,4,5\}$ \\
\hline 11 & $P_{1}=\{1,2,3\}, P_{2}=\{1,2,4,5\}, P_{3}=\{1,3,4,5\}, P_{4}=\{2,3,4,5\}$ \\
\hline 12 & $P_{1}=\{1,2,3\}, P_{2}=\{1,2,4\}, P_{3}=\{1,2,5\}, P_{4}=\{1,3,4,5\}$ \\
\hline 13 & $P_{1}=\{1,2,3\}, P_{2}=\{1,2,4\}, P_{3}=\{1,3,5\}$ \\
\hline 14 & $P_{1}=\{1,2,3\}, P_{2}=\{1,2,4\}, P_{3}=\{1,3,4,5\}, P_{4}=\{2,3,4,5\}$ \\
\hline 15 & $P_{1}=\{1,2,3\}, P_{2}=\{1,4,5\}, P_{3}=\{2,3,4,5\}$ \\
\hline 16 & $P_{1}=\{1,2,3\}, P_{2}=\{1,2,4\}, P_{3}=\{1,3,5\}, P_{4}=\{1,4,5\}$ \\
\hline 17 & $P_{1}=\{1,2,3\}, P_{2}=\{1,2,4\}, P_{3}=\{1,2,5\}, P_{4}=\{1,3,4\}$ \\
\hline 18 & $P_{1}=\{1,2,3\}, P_{2}=\{1,2,4\}, P_{3}=\{1,2,5\}, P_{4}=\{1,3,4,5\}, P_{5}=\{2,3,4,5\}$ \\
\hline 19 & $P_{1}=\{1,2,3\}, P_{2}=\{1,2,4\}, P_{3}=\{1,3,5\}, P_{4}=\{2,3,4,5\}$ \\
\hline 20 & $P_{1}=\{1,2,3\}, P_{2}=\{1,2,4\}, P_{3}=\{1,3,4\}, P_{4}=\{2,3,4,5\}$ \\
\hline 21 & $P_{1}=\{1,2,3\}, P_{2}=\{1,2,4\}, P_{3}=\{3,4,5\}$ \\
\hline 22 & $P_{1}=\{1,2\}, P_{2}=\{1,3,4,5\}$ \\
\hline 23 & $P_{1}=\{1,2,3\}, P_{2}=\{1,2,4\}, P_{3}=\{1,2,5\}, P_{4}=\{1,3,4\}, P_{5}=\{1,3,5\}$ \\
\hline 24 & $P_{1}=\{1,2,3\}, P_{2}=\{1,2,4\}, P_{3}=\{1,3,5\}, P_{4}=\{1,4,5\}, P_{5}=\{2,3,4,5\}$ \\
\hline 25 & $P_{1}=\{1,2,3\}, P_{2}=\{1,2,4\}, P_{3}=\{1,2,5\}, P_{4}=\{1,3,4\}, P_{5}=\{2,3,4,5\}$ \\
\hline 26 & $P_{1}=\{1,2,3\}, P_{2}=\{1,2,4\}, P_{3}=\{1,3,5\}, P_{4}=\{2,4,5\}$ \\
\hline 27 & $P_{1}=\{1,2,3\}, P_{2}=\{1,2,4\}, P_{3}=\{1,3,4\}, P_{4}=\{2,3,5\}$ \\
\hline 28 & $P_{1}=\{1,2,3\}, P_{2}=\{1,2,4\}, P_{3}=\{1,2,5\}, P_{4}=\{3,4,5\}$ \\
\hline
\end{tabular}

Continues next page 


\begin{tabular}{|c|c|}
\hline $\mathrm{N}$ & Minimal path sets \\
\hline 29 & $P_{1}=\{1,2,3\}, P_{2}=\{1,2,4\}, P_{3}=\{1,2,5\}, P_{4}=\{1,3,4\}, P_{5}=\{1,3,5\}, P_{6}=\{1,4,5\}$ \\
\hline 30 & $P_{1}=\{1,2\}, P_{2}=\{1,3,4,5\}, P_{3}=\{2,3,4,5\}$ \\
\hline 31 & $P_{1}=\{1,2\}, P_{2}=\{1,3,4\}, P_{3}=\{1,3,5\}$ \\
\hline 32 & $\begin{array}{l}P_{1}=\{1,2,3\}, P_{2}=\{1,2,4\}, P_{3}=\{1,2,5\}, P_{4}=\{1,3,4\}, P_{5}=\{1,3,5\} \\
P_{6}=\{2,3,4,5\}\end{array}$ \\
\hline 33 & $P_{1}=\{1,2,3\}, P_{2}=\{1,2,4\}, P_{3}=\{1,3,5\}, P_{4}=\{2,4,5\}, P_{5}=\{3,4,5\}$ \\
\hline 34 & $P_{1}=\{1,2,3\}, P_{2}=\{1,2,4\}, P_{3}=\{1,3,4\}, P_{4}=\{2,3,5\}, P_{5}=\{2,4,5\}$ \\
\hline 35 & $P_{1}=\{1,2,3\}, P_{2}=\{1,2,4\}, P_{3}=\{1,2,5\}, P_{4}=\{1,3,4\}, P_{5}=\{3,4,5\}$ \\
\hline 36 & $P_{1}=\{1,2,3\}, P_{2}=\{1,2,4\}, P_{3}=\{1,2,5\}, P_{4}=\{1,3,4\}, P_{5}=\{2,3,5\}$ \\
\hline 37 & $P_{1}=\{1,2,3\}, P_{2}=\{1,2,4\}, P_{3}=\{1,2,5\}, P_{4}=\{1,3,4\}, P_{5}=\{2,3,4\}$ \\
\hline 38 & $P_{1}=\{1,2\}, P_{2}=\{1,3,4\}, P_{3}=\{2,3,4,5\}$ \\
\hline 39 & $P_{1}=\{1,2\}, P_{2}=\{3,4,5\}$ \\
\hline 40 & $\begin{array}{l}P_{1}=\{1,2,3\}, P_{2}=\{1,2,4\}, P_{3}=\{1,2,5\}, P_{4}=\{1,3,4\}, P_{5}=\{1,3,5\}, P_{6}=\{1,4,5\} \\
P_{7}=\{2,3,4,5\}\end{array}$ \\
\hline 41 & $P_{1}=\{1,2,3\}, P_{2}=\{1,2,4\}, P_{3}=\{1,3,4\}, P_{4}=\{2,3,5\}, P_{5}=\{2,4,5\}, P_{6}=\{3,4,5\}$ \\
\hline 42 & $P_{1}=\{1,2,3\}, P_{2}=\{1,2,4\}, P_{3}=\{1,2,5\}, P_{4}=\{1,3,4\}, P_{5}=\{2,3,5\}, P_{6}=\{3,4,5\}$ \\
\hline 43 & $P_{1}=\{1,2,3\}, P_{2}=\{1,2,4\}, P_{3}=\{1,2,5\}, P_{4}=\{1,3,4\}, P_{5}=\{2,3,4\}, P_{6}=\{3,4,5\}$ \\
\hline 44 & $P_{1}=\{1,2,3\}, P_{2}=\{1,2,4\}, P_{3}=\{1,2,5\}, P_{4}=\{1,3,4\}, P_{5}=\{1,3,5\}, P_{6}=\{2,4,5\}$ \\
\hline 45 & $P_{1}=\{1,2,3\}, P_{2}=\{1,2,4\}, P_{3}=\{1,2,5\}, P_{4}=\{1,3,4\}, P_{5}=\{1,3,5\}, P_{6}=\{2,3,4\}$ \\
\hline 46 & $P_{1}=\{1,2\}, P_{2}=\{1,3,4\}, P_{3}=\{1,3,5\}, P_{4}=\{1,4,5\}$ \\
\hline 47 & $P_{1}=\{1,2\}, P_{2}=\{1,3,4\}, P_{3}=\{1,3,5\}, P_{4}=\{2,3,4,5\}$ \\
\hline 48 & $P_{1}=\{1,2\}, P_{2}=\{1,3,4\}, P_{3}=\{3,4,5\}$ \\
\hline 49 & $P_{1}=\{1,2\}, P_{2}=\{1,3,4\}, P_{3}=\{2,3,5\}$ \\
\hline 50 & $\begin{array}{l}P_{1}=\{1,2,3\}, P_{2}=\{1,2,4\}, P_{3}=\{1,2,5\}, P_{4}=\{1,3,4\}, P_{5}=\{1,3,5\}, P_{6}=\{2,4,5\} \\
P_{7}=\{3,4,5\}\end{array}$ \\
\hline 51 & $\begin{array}{l}P_{1}=\{1,2,3\}, P_{2}=\{1,2,4\}, P_{3}=\{1,2,5\}, P_{4}=\{1,3,4\}, P_{5}=\{1,3,5\}, P_{6}=\{2,3,4\}, \\
P_{7}=\{2,4,5\}\end{array}$ \\
\hline 52 & $\begin{array}{l}P_{1}=\{1,2,3\}, P_{2}=\{1,2,4\}, P_{3}=\{1,2,5\}, P_{4}=\{1,3,4\}, P_{5}=\{1,3,5\}, P_{6}=\{2,3,4\} \\
P_{7}=\{2,3,5\}\end{array}$ \\
\hline 53 & $\begin{array}{l}P_{1}=\{1,2,3\}, P_{2}=\{1,2,4\}, P_{3}=\{1,2,5\}, P_{4}=\{1,3,4\}, P_{5}=\{1,3,5\}, P_{6}=\{1,4,5\} \\
P_{7}=\{2,3,4\}\end{array}$ \\
\hline
\end{tabular}

Continues next page 


\begin{tabular}{|c|c|}
\hline $\mathrm{N}$ & Minimal path sets \\
\hline 54 & $P_{1}=\{1,2\}, P_{2}=\{1,3,4\}, P_{3}=\{1,3,5\}, P_{4}=\{1,4,5\}, P_{5}=\{2,3,4,5\}$ \\
\hline 55 & $P_{1}=\{1,2\}, P_{2}=\{1,3,4\}, P_{3}=\{2,3,5\}, P_{4}=\{3,4,5\}$ \\
\hline 56 & $P_{1}=\{1,2\}, P_{2}=\{1,3,4\}, P_{3}=\{2,3,4\}, P_{4}=\{3,4,5\}$ \\
\hline 57 & $P_{1}=\{1,2\}, P_{2}=\{1,3,4\}, P_{3}=\{1,3,5\}, P_{4}=\{3,4,5\}$ \\
\hline 58 & $P_{1}=\{1,2\}, P_{2}=\{1,3,4\}, P_{3}=\{1,3,5\}, P_{4}=\{2,4,5\}$ \\
\hline 59 & $P_{1}=\{1,2\}, P_{2}=\{1,3,4\}, P_{3}=\{1,3,5\}, P_{4}=\{2,3,4\}$ \\
\hline 60 & $P_{1}=\{1,2\}, P_{2}=\{1,3\}, P_{3}=\{1,4,5\}$ \\
\hline 61 & $\begin{array}{l}P_{1}=\{1,2,3\}, P_{2}=\{1,2,4\}, P_{3}=\{1,2,5\}, P_{4}=\{1,3,4\}, P_{5}=\{1,3,5\}, P_{6}=\{2,3,4\} \\
P_{7}=\{2,4,5\}, P_{8}=\{3,4,5\}\end{array}$ \\
\hline 62 & $\begin{array}{l}P_{1}=\{1,2,3\}, P_{2}=\{1,2,4\}, P_{3}=\{1,2,5\}, P_{4}=\{1,3,4\}, P_{5}=\{1,3,5\}, P_{6}=\{1,4,5\} \\
P_{7}=\{2,3,4\}, P_{8}=\{2,3,5\}\end{array}$ \\
\hline 63 & $P_{1}=\{1,2\}, P_{2}=\{1,3\}, P_{3}=\{2,3,4,5\}$ \\
\hline 64 & $P_{1}=\{1,2\}, P_{2}=\{1,3,4\}, P_{3}=\{1,3,5\}, P_{4}=\{2,4,5\}, P_{5}=\{3,4,5\}$ \\
\hline 65 & $P_{1}=\{1,2\}, P_{2}=\{1,3,4\}, P_{3}=\{1,3,5\}, P_{4}=\{2,3,4\}, P_{5}=\{3,4,5\}$ \\
\hline 66 & $P_{1}=\{1,2\}, P_{2}=\{1,3,4\}, P_{3}=\{1,3,5\}, P_{4}=\{2,3,4\}, P_{5}=\{2,4,5\}$ \\
\hline 67 & $P_{1}=\{1,2\}, P_{2}=\{1,3,4\}, P_{3}=\{1,3,5\}, P_{4}=\{2,3,4\}, P_{5}=\{2,3,5\}$ \\
\hline 68 & $P_{1}=\{1,2\}, P_{2}=\{1,3,4\}, P_{3}=\{1,3,5\}, P_{4}=\{1,4,5\}, P_{5}=\{3,4,5\}$ \\
\hline 69 & $P_{1}=\{1,2\}, P_{2}=\{1,3,4\}, P_{3}=\{1,3,5\}, P_{4}=\{1,4,5\}, P_{5}=\{2,3,4\}$ \\
\hline 70 & $\begin{array}{l}P_{1}=\{1,2,3\}, P_{2}=\{1,2,4\}, P_{3}=\{1,2,5\}, P_{4}=\{1,3,4\}, P_{5}=\{1,3,5\}, P_{6}=\{1,4,5\} \\
P_{7}=\{2,3,4\}, P_{8}=\{2,3,5\}, P_{9}=\{2,4,5\}\end{array}$ \\
\hline 71 & $P_{1}=\{1,2\}, P_{2}=\{1,3\}, P_{3}=\{1,4,5\}, P_{4}=\{2,3,4,5\}$ \\
\hline 72 & $P_{1}=\{1,2\}, P_{2}=\{1,3\}, P_{3}=\{2,4,5\}$ \\
\hline 73 & $P_{1}=\{1,2\}, P_{2}=\{1,3,4\}, P_{3}=\{1,3,5\}, P_{4}=\{2,3,4\}, P_{5}=\{2,4,5\}, P_{6}=\{3,4,5\}$ \\
\hline 74 & $P_{1}=\{1,2\}, P_{2}=\{1,3,4\}, P_{3}=\{1,3,5\}, P_{4}=\{2,3,4\}, P_{5}=\{2,3,5\}, P_{6}=\{3,4,5\}$ \\
\hline 75 & $P_{1}=\{1,2\}, P_{2}=\{1,3,4\}, P_{3}=\{1,3,5\}, P_{4}=\{1,4,5\}, P_{5}=\{2,3,4\}, P_{6}=\{3,4,5\}$ \\
\hline 76 & $P_{1}=\{1,2\}, P_{2}=\{1,3,4\}, P_{3}=\{1,3,5\}, P_{4}=\{1,4,5\}, P_{5}=\{2,3,4\}, P_{6}=\{2,3,5\}$ \\
\hline 77 & $P_{1}=\{1,2\}, P_{2}=\{1,3\}, P_{3}=\{2,4,5\}, P_{4}=\{3,4,5\}$ \\
\hline 78 & $P_{1}=\{1,2\}, P_{2}=\{1,3\}, P_{3}=\{2,3,4\}, P_{4}=\{2,4,5\}$ \\
\hline 79 & $P_{1}=\{1,2\}, P_{2}=\{1,3\}, P_{3}=\{2,3,4\}, P_{4}=\{2,3,5\}$ \\
\hline 80 & $P_{1}=\{1,2\}, P_{2}=\{1,3\}, P_{3}=\{1,4,5\}, P_{4}=\{2,4,5\}$ \\
\hline 81 & $P_{1}=\{1,2\}, P_{2}=\{1,3\}, P_{3}=\{1,4,5\}, P_{4}=\{2,3,4\}$ \\
\hline
\end{tabular}

Continues next page

17

URL: http://mc.manuscriptcentral.com/Issp E-mail: comstat@univmail.cis.mcmaster.ca 


\begin{tabular}{|c|c|}
\hline $\mathrm{N}$ & Minimal path sets \\
\hline 82 & $P_{1}=\{1,2\}, P_{2}=\{3,4\}, P_{3}=\{1,3,5\}$ \\
\hline 83 & $\begin{array}{l}P_{1}=\{1,2,3\}, P_{2}=\{1,2,4\}, P_{3}=\{1,2,5\}, P_{4}=\{1,3,4\}, P_{5}=\{1,3,5\}, P_{6}=\{1,4,5\}, \\
P_{7}=\{2,3,4\}, P_{8}=\{2,3,5\}, P_{9}=\{2,4,5\}, P_{10}=\{3,4,5\}\end{array}$ \\
\hline 84 & $\begin{array}{l}P_{1}=\{1,2\}, P_{2}=\{1,3,4\}, P_{3}=\{1,3,5\}, P_{4}=\{1,4,5\}, P_{5}=\{2,3,4\}, P_{6}=\{2,3,5\} \\
P_{7}=\{3,4,5\}\end{array}$ \\
\hline 85 & $\begin{array}{l}P_{1}=\{1,2\}, P_{2}=\{1,3,4\}, P_{3}=\{1,3,5\}, P_{4}=\{1,4,5\}, P_{5}=\{2,3,4\}, P_{6}=\{2,3,5\} \\
P_{7}=\{2,4,5\}\end{array}$ \\
\hline 86 & $P_{1}=\{1,2\}, P_{2}=\{1,3\}, P_{3}=\{1,4\}, P_{4}=\{2,3,4,5\}$ \\
\hline 87 & $P_{1}=\{1,2\}, P_{2}=\{1,3\}, P_{3}=\{1,4\}, P_{4}=\{1,5\}$ \\
\hline 88 & $P_{1}=\{1,2\}, P_{2}=\{1,3\}, P_{3}=\{2,3,4\}, P_{4}=\{2,4,5\}, P_{5}=\{3,4,5\}$ \\
\hline 89 & $P_{1}=\{1,2\}, P_{2}=\{1,3\}, P_{3}=\{2,3,4\}, P_{4}=\{2,3,5\}, P_{5}=\{2,4,5\}$ \\
\hline 90 & $P_{1}=\{1,2\}, P_{2}=\{1,3\}, P_{3}=\{1,4,5\}, P_{4}=\{2,4,5\}, P_{5}=\{3,4,5\}$ \\
\hline 91 & $P_{1}=\{1,2\}, P_{2}=\{1,3\}, P_{3}=\{1,4,5\}, P_{4}=\{2,3,4\}, P_{5}=\{2,4,5\}$ \\
\hline 92 & $P_{1}=\{1,2\}, P_{2}=\{1,3\}, P_{3}=\{1,4,5\}, P_{4}=\{2,3,4\}, P_{5}=\{2,3,5\}$ \\
\hline 93 & $P_{1}=\{1,2\}, P_{2}=\{3,4\}, P_{3}=\{1,3,5\}, P_{4}=\{2,4,5\}$ \\
\hline 94 & $P_{1}=\{1,2\}, P_{2}=\{3,4\}, P_{3}=\{1,3,5\}, P_{4}=\{1,4,5\}$ \\
\hline 95 & $P_{1}=\{1,2\}, P_{2}=\{1,3\}, P_{3}=\{1,4\}, P_{4}=\{2,3,5\}$ \\
\hline 96 & $\begin{array}{l}P_{1}=\{1,2\}, P_{2}=\{1,3,4\}, P_{3}=\{1,3,5\}, P_{4}=\{1,4,5\}, P_{5}=\{2,3,4\}, P_{6}=\{2,3,5\} \\
P_{7}=\{2,4,5\}, P_{8}=\{3,4,5\}\end{array}$ \\
\hline 97 & $P_{1}=\{1,2\}, P_{2}=\{1,3\}, P_{3}=\{2,3,4\}, P_{4}=\{2,3,5\}, P_{5}=\{2,4,5\}, P_{6}=\{3,4,5\}$ \\
\hline 98 & $P_{1}=\{1,2\}, P_{2}=\{1,3\}, P_{3}=\{1,4,5\}, P_{4}=\{2,3,4\}, P_{5}=\{2,4,5\}, P_{6}=\{3,4,5\}$ \\
\hline 99 & $P_{1}=\{1,2\}, P_{2}=\{1,3\}, P_{3}=\{1,4,5\}, P_{4}=\{2,3,4\}, P_{5}=\{2,3,5\}, P_{6}=\{2,4,5\}$ \\
\hline 100 & $P_{1}=\{1,2\}, P_{2}=\{3,4\}, P_{3}=\{1,3,5\}, P_{4}=\{1,4,5\}, P_{5}=\{2,3,5\}$ \\
\hline 101 & $P_{1}=\{1,2\}, P_{2}=\{1,3\}, P_{3}=\{1,4\}, P_{4}=\{1,5\}, P_{5}=\{2,3,4,5\}$ \\
\hline 102 & $P_{1}=\{1,2\}, P_{2}=\{1,3\}, P_{3}=\{1,4\}, P_{4}=\{2,3,5\}, P_{5}=\{2,4,5\}$ \\
\hline 103 & $P_{1}=\{1,2\}, P_{2}=\{1,3\}, P_{3}=\{1,4\}, P_{4}=\{2,3,4\}, P_{5}=\{2,3,5\}$ \\
\hline 104 & $P_{1}=\{1,2\}, P_{2}=\{1,3\}, P_{3}=\{2,4\}, P_{4}=\{3,4,5\}$ \\
\hline 105 & $P_{1}=\{1,2\}, P_{2}=\{1,3\}, P_{3}=\{2,4\}, P_{4}=\{1,4,5\}$ \\
\hline 106 & $P_{1}=\{1,2\}, P_{2}=\{1,3\}, P_{3}=\{2,3\}, P_{4}=\{1,4,5\}$ \\
\hline 107 & $P_{1}=\{1,2\}, P_{2}=\{1,3\}, P_{3}=\{4,5\}$ \\
\hline 108 & $P_{1}=\{1,2\}, P_{2}=\{1,3\}, P_{3}=\{1,4,5\}, P_{4}=\{2,3,4\}, P_{5}=\{2,3,5\}, P_{6}=\{2,4,5\}$ \\
\hline
\end{tabular}




\begin{tabular}{|c|c|}
\hline $\mathrm{N}$ & Minimal path sets \\
\hline & $P_{7}=\{3,4,5\}$ \\
\hline 109 & $P_{1}=\{1,2\}, P_{2}=\{3,4\}, P_{3}=\{1,3,5\}, P_{4}=\{1,4,5\}, P_{5}=\{2,3,5\}, P_{6}=\{2,4,5\}$ \\
\hline 110 & $P_{1}=\{1,2\}, P_{2}=\{1,3\}, P_{3}=\{1,4\}, P_{4}=\{1,5\}, P_{5}=\{2,3,4\}$ \\
\hline 111 & $P_{1}=\{1,2\}, P_{2}=\{1,3\}, P_{3}=\{1,4\}, P_{4}=\{2,3,5\}, P_{5}=\{2,4,5\}, P_{6}=\{3,4,5\}$ \\
\hline 112 & $P_{1}=\{1,2\}, P_{2}=\{1,3\}, P_{3}=\{1,4\}, P_{4}=\{2,3,4\}, P_{5}=\{2,3,5\}, P_{6}=\{2,4,5\}$ \\
\hline 113 & $P_{1}=\{1,2\}, P_{2}=\{1,3\}, P_{3}=\{2,4\}, P_{4}=\{1,4,5\}, P_{5}=\{3,4,5\}$ \\
\hline 114 & $P_{1}=\{1,2\}, P_{2}=\{1,3\}, P_{3}=\{2,4\}, P_{4}=\{1,4,5\}, P_{5}=\{2,3,5\}$ \\
\hline 115 & $P_{1}=\{1,2\}, P_{2}=\{1,3\}, P_{3}=\{2,3\}, P_{4}=\{1,4,5\}, P_{5}=\{2,4,5\}$ \\
\hline 116 & $P_{1}=\{1,2\}, P_{2}=\{1,3\}, P_{3}=\{4,5\}, P_{4}=\{2,3,4\}$ \\
\hline 117 & $P_{1}=\{1,2\}, P_{2}=\{1,3\}, P_{3}=\{1,4\}, P_{4}=\{1,5\}, P_{5}=\{2,3,4\}, P_{6}=\{2,3,5\}$ \\
\hline 118 & $P_{1}=\{1,2\}, P_{2}=\{1,3\}, P_{3}=\{1,4\}, P_{4}=\{2,5\}$ \\
\hline 119 & $\begin{array}{l}P_{1}=\{1,2\}, P_{2}=\{1,3\}, P_{3}=\{1,4\}, P_{4}=\{2,3,4\}, P_{5}=\{2,3,5\}, P_{6}=\{2,4,5\} \\
P_{7}=\{3,4,5\}\end{array}$ \\
\hline 120 & $P_{1}=\{1,2\}, P_{2}=\{1,3\}, P_{3}=\{2,4\}, P_{4}=\{1,4,5\}, P_{5}=\{2,3,5\}, P_{6}=\{3,4,5\}$ \\
\hline 121 & $P_{1}=\{1,2\}, P_{2}=\{1,3\}, P_{3}=\{2,3\}, P_{4}=\{1,4,5\}, P_{5}=\{2,4,5\}, P_{6}=\{3,4,5\}$ \\
\hline 122 & $P_{1}=\{1,2\}, P_{2}=\{1,3\}, P_{3}=\{4,5\}, P_{4}=\{2,3,4\}, P_{5}=\{2,3,5\}$ \\
\hline 123 & $\begin{array}{l}P_{1}=\{1,2\}, P_{2}=\{1,3\}, P_{3}=\{1,4\}, P_{4}=\{1,5\}, P_{5}=\{2,3,4\}, P_{6}=\{2,3,5\} \\
P_{7}=\{2,4,5\}\end{array}$ \\
\hline 124 & $P_{1}=\{1,2\}, P_{2}=\{1,3\}, P_{3}=\{2,4\}, P_{4}=\{3,4\}, P_{5}=\{1,4,5\}$ \\
\hline 125 & $P_{1}=\{1,2\}, P_{2}=\{1,3\}, P_{3}=\{1,4\}, P_{4}=\{2,5\}, P_{5}=\{3,4,5\}$ \\
\hline 126 & $P_{1}=\{1,2\}, P_{2}=\{1,3\}, P_{3}=\{1,4\}, P_{4}=\{2,5\}, P_{5}=\{2,3,4\}$ \\
\hline 127 & $P_{1}=\{1,2\}, P_{2}=\{1,3\}, P_{3}=\{1,4\}, P_{4}=\{2,3\}, P_{5}=\{2,4,5\}$ \\
\hline 128 & $P_{1}=\{1,2\}, P_{2}=\{1,3\}, P_{3}=\{2,4\}, P_{4}=\{3,5\}$ \\
\hline 129 & $P_{1}=\{1,2\}, P_{2}=\{1,3\}, P_{3}=\{1,4\}, P_{4}=\{1,5\}, P_{5}=\{2,3\}$ \\
\hline 130 & $\begin{array}{l}P_{1}=\{1,2\}, P_{2}=\{1,3\}, P_{3}=\{1,4\}, P_{4}=\{1,5\}, P_{5}=\{2,3,4\}, P_{6}=\{2,3,5\} \\
P_{7}=\{2,4,5\}, P_{8}=\{3,4,5\}\end{array}$ \\
\hline 131 & $P_{1}=\{1,2\}, P_{2}=\{1,3\}, P_{3}=\{2,4\}, P_{4}=\{3,4\}, P_{5}=\{1,4,5\}, P_{6}=\{2,3,5\}$ \\
\hline 132 & $P_{1}=\{1,2\}, P_{2}=\{1,3\}, P_{3}=\{1,4\}, P_{4}=\{2,5\}, P_{5}=\{2,3,4\}, P_{6}=\{3,4,5\}$ \\
\hline 133 & $P_{1}=\{1,2\}, P_{2}=\{1,3\}, P_{3}=\{1,4\}, P_{4}=\{2,3\}, P_{5}=\{2,4,5\}, P_{6}=\{3,4,5\}$ \\
\hline 134 & $P_{1}=\{1,2\}, P_{2}=\{1,3\}, P_{3}=\{2,4\}, P_{4}=\{3,5\}, P_{5}=\{1,4,5\}$ \\
\hline 135 & $P_{1}=\{1,2\}, P_{2}=\{1,3\}, P_{3}=\{2,3\}, P_{4}=\{4,5\}$ \\
\hline
\end{tabular}

Continues next page 


\begin{tabular}{|c|c|}
\hline $\mathrm{N}$ & Minimal path sets \\
\hline 136 & $P_{1}=\{1,2\}, P_{2}=\{1,3\}, P_{3}=\{1,4\}, P_{4}=\{1,5\}, P_{5}=\{2,3\}, P_{6}=\{2,4,5\}$ \\
\hline 137 & $P_{1}=\{1,2\}, P_{2}=\{1,3\}, P_{3}=\{1,4\}, P_{4}=\{2,5\}, P_{5}=\{3,5\}$ \\
\hline 138 & $P_{1}=\{1,2\}, P_{2}=\{1,3\}, P_{3}=\{1,4\}, P_{4}=\{2,3\}, P_{5}=\{2,5\}$ \\
\hline 139 & $\begin{array}{l}P_{1}=\{1,2\}, P_{2}=\{1,3\}, P_{3}=\{1,4\}, P_{4}=\{1,5\}, P_{5}=\{2,3\}, P_{6}=\{2,4,5\} \\
P_{7}=\{3,4,5\}\end{array}$ \\
\hline 140 & $P_{1}=\{1,2\}, P_{2}=\{1,3\}, P_{3}=\{1,4\}, P_{4}=\{2,5\}, P_{5}=\{3,5\}, P_{6}=\{2,3,4\}$ \\
\hline 141 & $P_{1}=\{1,2\}, P_{2}=\{1,3\}, P_{3}=\{1,4\}, P_{4}=\{2,3\}, P_{5}=\{2,5\}, P_{6}=\{3,4,5\}$ \\
\hline 142 & $P_{1}=\{1,2\}, P_{2}=\{1,3\}, P_{3}=\{1,4\}, P_{4}=\{2,3\}, P_{5}=\{2,4\}, P_{6}=\{3,4,5\}$ \\
\hline 143 & $P_{1}=\{1,2\}, P_{2}=\{1,3\}, P_{3}=\{2,4\}, P_{4}=\{3,5\}, P_{5}=\{4,5\}$ \\
\hline 144 & $P_{1}=\{1,2\}, P_{2}=\{1,3\}, P_{3}=\{1,4\}, P_{4}=\{2,3\}, P_{5}=\{4,5\}$ \\
\hline 145 & $P_{1}=\{1,2\}, P_{2}=\{1,3\}, P_{3}=\{1,4\}, P_{4}=\{2,5\}, P_{5}=\{3,5\}, P_{6}=\{4,5\}$ \\
\hline 146 & $P_{1}=\{1,2\}, P_{2}=\{1,3\}, P_{3}=\{1,4\}, P_{4}=\{1,5\}, P_{5}=\{2,3\}, P_{6}=\{2,4\}$ \\
\hline 147 & $P_{1}=\{1\}, P_{2}=\{2,3,4,5\}$ \\
\hline 148 & $\begin{array}{l}P_{1}=\{1,2\}, P_{2}=\{1,3\}, P_{3}=\{1,4\}, P_{4}=\{2,5\}, P_{5}=\{3,5\}, P_{6}=\{4,5\} \\
P_{7}=\{2,3,4\}\end{array}$ \\
\hline 149 & $\begin{array}{l}P_{1}=\{1,2\}, P_{2}=\{1,3\}, P_{3}=\{1,4\}, P_{4}=\{1,5\}, P_{5}=\{2,3\}, P_{6}=\{2,4\} \\
P_{7}=\{3,4,5\}\end{array}$ \\
\hline 150 & $P_{1}=\{1,2\}, P_{2}=\{1,3\}, P_{3}=\{1,4\}, P_{4}=\{2,3\}, P_{5}=\{2,5\}, P_{6}=\{4,5\}$ \\
\hline 151 & $P_{1}=\{1,2\}, P_{2}=\{1,3\}, P_{3}=\{1,4\}, P_{4}=\{2,3\}, P_{5}=\{2,4\}, P_{6}=\{3,5\}$ \\
\hline 152 & $P_{1}=\{1,2\}, P_{2}=\{1,3\}, P_{3}=\{1,4\}, P_{4}=\{1,5\}, P_{5}=\{2,3\}, P_{6}=\{4,5\}$ \\
\hline 153 & $P_{1}=\{1,2\}, P_{2}=\{1,3\}, P_{3}=\{1,4\}, P_{4}=\{1,5\}, P_{5}=\{2,3\}, P_{6}=\{2,4\}, P_{7}$ \\
\hline 154 & $P_{1}=\{1\}, P_{2}=\{2,3,4\}, P_{3}=\{2,3,5\}$ \\
\hline 155 & $\begin{array}{l}P_{1}=\{1,2\}, P_{2}=\{1,3\}, P_{3}=\{1,4\}, P_{4}=\{1,5\}, P_{5}=\{2,3\}, P_{6}=\{2,4\}, P_{7}=\{2,5\} \\
P_{8}=\{3,4,5\}\end{array}$ \\
\hline 156 & $P_{1}=\{1,2\}, P_{2}=\{1,3\}, P_{3}=\{1,4\}, P_{4}=\{2,3\}, P_{5}=\{2,4\}, P_{6}=\{3,5\}, P_{7}=\{4,5\}$ \\
\hline 157 & $P_{1}=\{1,2\}, P_{2}=\{1,3\}, P_{3}=\{1,4\}, P_{4}=\{1,5\}, P_{5}=\{2,3\}, P_{6}=\{2,4\}, P_{7}=\{3,5\}$ \\
\hline 158 & $P_{1}=\{1,2\}, P_{2}=\{1,3\}, P_{3}=\{1,4\}, P_{4}=\{1,5\}, P_{5}=\{2,3\}, P_{6}=\{2,4\}, P_{7}=\{3,4\}$ \\
\hline 159 & $P_{1}=\{1\}, P_{2}=\{2,3,4\}, P_{3}=\{2,3,5\}, P_{4}=\{2,4,5\}$ \\
\hline 160 & $\begin{array}{l}P_{1}=\{1,2\}, P_{2}=\{1,3\}, P_{3}=\{1,4\}, P_{4}=\{1,5\}, P_{5}=\{2,3\}, P_{6}=\{2,4\}, P_{7}=\{3,5\} \\
P_{8}=\{4,5\}\end{array}$ \\
\hline 161 & $P_{1}=\{1,2\}, P_{2}=\{1,3\}, P_{3}=\{1,4\}, P_{4}=\{1,5\}, P_{5}=\{2,3\}, P_{6}=\{2,4\}, P_{7}=\{2,5\}$, \\
\hline
\end{tabular}




\begin{tabular}{|c|l|}
\hline $\mathrm{N}$ & Minimal path sets \\
\hline & $P_{8}=\{3,4\}$ \\
\hline 162 & $P_{1}=\{1\}, P_{2}=\{2,3,4\}, P_{3}=\{2,3,5\}, P_{4}=\{2,4,5\}, P_{5}=\{3,4,5\}$ \\
\hline 163 & $P_{1}=\{1\}, P_{2}=\{2,3\}, P_{3}=\{2,4,5\}$ \\
\hline 164 & $P_{1}=\{1,2\}, P_{2}=\{1,3\}, P_{3}=\{1,4\}, P_{4}=\{1,5\}, P_{5}=\{2,3\}, P_{6}=\{2,4\}, P_{7}=\{2,5\}$, \\
& $P_{8}=\{3,4\}, P_{9}=\{3,5\}$ \\
\hline 165 & $P_{1}=\{1\}, P_{2}=\{2,3\}, P_{3}=\{2,4,5\}, P_{4}=\{3,4,5\}$ \\
\hline 166 & $P_{1}=\{1,2\}, P_{2}=\{1,3\}, P_{3}=\{1,4\}, P_{4}=\{1,5\}, P_{5}=\{2,3\}, P_{6}=\{2,4\}, P_{7}=\{2,5\}$, \\
\hline 167 & $P_{8}=\{3,4\}, P_{9}=\{3,5\}, P_{10}=\{4,5\}$ \\
\hline 168 & $P_{1}=\{1\}, P_{2}=\{2,3\}, P_{3}=\{4,5\}$ \\
\hline 169 & $P_{1}=\{1\}, P_{2}=\{2,3\}, P_{3}=\{2,4\}, P_{4}=\{2,5\}$ \\
\hline 170 & $P_{1}=\{1\}, P_{2}=\{2,3\}, P_{3}=\{2,4\}, P_{4}=\{2,5\}, P_{5}=\{3,4,5\}$ \\
\hline 171 & $P_{1}=\{1\}, P_{2}=\{2,3\}, P_{3}=\{2,4\}, P_{4}=\{3,5\}$ \\
\hline 172 & $P_{1}=\{1\}, P_{2}=\{2,3\}, P_{3}=\{2,4\}, P_{4}=\{3,5\}, P_{5}=\{4,5\}$ \\
\hline 173 & $P_{1}=\{1\}, P_{2}=\{2,3\}, P_{3}=\{2,4\}, P_{4}=\{2,5\}, P_{5}=\{3,4\}$ \\
\hline 174 & $P_{1}=\{1\}, P_{2}=\{2,3\}, P_{3}=\{2,4\}, P_{4}=\{2,5\}, P_{5}=\{3,4\}, P_{6}=\{3,5\}$ \\
\hline 175 & $P_{1}=\{1\}, P_{2}=\{2,3\}, P_{3}=\{2,4\}, P_{4}=\{2,5\}, P_{5}=\{3,4\}, P_{6}=\{3,5\}, P_{7}=\{4,5\}$ \\
\hline 176 & $P_{1}=\{1\}, P_{2}=\{2\}, P_{3}=\{3,4,5\}$ \\
\hline 177 & $P_{1}=\{1\}, P_{2}=\{2\}, P_{3}=\{3,4\}, P_{4}=\{3,5\}$ \\
\hline 178 & $P_{1}=\{1\}, P_{2}=\{2\}, P_{3}=\{3,4\}, P_{4}=\{3,5\}, P_{5}=\{4,5\}$ \\
\hline 179 & $P_{1}=\{1\}, P_{2}=\{2\}, P_{3}=\{3\}, P_{4}=\{4,5\}$ \\
\hline 180 & $P_{1}=\{1\}, P_{2}=\{2\}, P_{3}=\{3\}, P_{4}=\{4\}, P_{5}=\{5\}$ \\
\hline
\end{tabular}


1

2

3

4

5

6

7

8

9

10

11

12

13

14

15

16

17

18

19

20

21

22

23

24

25

26

27

28

29

30

31

32

33

34

35

36

37

38

39

40

41

42

43

44

45

46

47

48

49

50

51

52

53

54

55

56

57

58

59

60

Table 2: Signatures of coherent systems with 5 exchangeable components. The systems are ordered by their expected lifetimes $E(T)$ in the case of IID exponential components with mean 1.

\begin{tabular}{|c|c|c|l|}
\hline $\mathrm{N}$ & $\mathbf{a}$ & $\mathbf{s}$ & $E(T)$ \\
\hline 1 & $(0,0,0,0,1)$ & $(1,0,0,0,0)$ & 0.2 \\
\hline 2 & $(0,0,0,2,-1)$ & $\left(\frac{3}{5}, \frac{2}{5}, 0,0,0\right)$ & 0.3 \\
\hline 3 & $(0,0,0,3,-2)$ & $\left(\frac{2}{5}, \frac{3}{5}, 0,0,0\right)$ & 0.35 \\
\hline 4 & $(0,0,1,1,-1)$ & $\left(\frac{2}{5}, \frac{1}{2}, \frac{1}{10}, 0,0\right)$ & 0.3833 \\
\hline 5 & $(0,0,0,4,-3)$ & $\left(\frac{1}{5}, \frac{4}{5}, 0,0,0\right)$ & 0.4 \\
\hline 6 & $(0,0,1,2,-2)$ & $\left(\frac{1}{5}, \frac{7}{10}, \frac{1}{10}, 0,0\right)$ & 0.4333 \\
\hline 7 & $(0,0,0,5,-4)$ & $(0,1,0,0,0)$ & 0.45 \\
\hline 8 & $(0,0,3,-3,1)$ & $\left(\frac{2}{5}, \frac{3}{10}, \frac{3}{10}, 0,0\right)$ & 0.45 \\
\hline $9-10$ & $(0,0,2,0,-1)$ & $\left(\frac{1}{5}, \frac{3}{5}, \frac{1}{5}, 0,0\right)$ & 0.4667 \\
\hline 11 & $(0,0,1,3,-3)$ & $\left(0, \frac{9}{10}, \frac{1}{10}, 0,0\right)$ & 0.4833 \\
\hline $12-13$ & $(0,0,3,-2,0)$ & $\left(\frac{1}{5}, \frac{1}{2}, \frac{3}{10}, 0,0\right)$ & 0.5 \\
\hline $14-15$ & $(0,0,2,1,-2)$ & $\left(0, \frac{4}{5}, \frac{1}{5}, 0,0\right)$ & 0.5167 \\
\hline $16-17$ & $(0,0,4,-4,1)$ & $\left(\frac{1}{5}, \frac{2}{5}, \frac{2}{5}, 0,0\right)$ & 0.5333 \\
\hline $18-21$ & $(0,0,3,-1,-1)$ & $\left(0, \frac{7}{10}, \frac{3}{10}, 0,0\right)$ & 0.55 \\
\hline 22 & $(0,1,0,1,-1)$ & $\left(\frac{1}{5}, \frac{1}{2}, \frac{1}{5}, \frac{1}{10}, 0\right)$ & 0.55 \\
\hline 23 & $(0,0,5,-6,2)$ & $\left(\frac{1}{5}, \frac{3}{10}, \frac{1}{2}, 0,0\right)$ & 0.5667 \\
\hline $24-28$ & $(0,0,4,-3,0)$ & $\left(0, \frac{3}{5}, \frac{2}{5}, 0,0\right)$ & 0.5833 \\
\hline 29 & $(0,0,6,-8,3)$ & $\left(\frac{1}{5}, \frac{1}{5}, \frac{3}{5}, 0,0\right)$ & 0.6 \\
\hline 30 & $(0,1,0,2,-2)$ & $\left(0, \frac{7}{10}, \frac{1}{5}, \frac{1}{10}, 0\right)$ & 0.6 \\
\hline 31 & $(0,1,2,-3,1)$ & $\left(\frac{1}{5}, \frac{3}{10}, \frac{2}{5}, \frac{1}{10}, 0\right)$ & 0.6167 \\
\hline $32-37$ & $(0,0,5,-5,1)$ & $\left(0, \frac{1}{2}, \frac{1}{2}, 0,0\right)$ & 0.6167 \\
\hline $38-39$ & $(0,1,1,0,-1)$ & $\left(0, \frac{3}{5}, \frac{3}{10}, \frac{1}{10}, 0\right)$ & 0.6333 \\
\hline $40-45$ & $(0,0,6,-7,2)$ & $\left(0, \frac{2}{5}, \frac{3}{5}, 0,0\right)$ & 0.65 \\
\hline 46 & $(0,1,3,-5,2)$ & $\left(\frac{1}{5}, \frac{1}{5}, \frac{1}{2}, \frac{1}{10}, 0\right)$ & 0.65 \\
\hline $47-49$ & $(0,1,2,-2,0)$ & $\left(0, \frac{1}{2}, \frac{2}{5}, \frac{1}{10}, 0\right)$ & 0.6667 \\
\hline $50-53$ & $(0,0,7,-9,3)$ & $\left(0, \frac{3}{10}, \frac{7}{10}, 0,0\right)$ & 0.6833 \\
\hline $54-59$ & $(0,1,3,-4,1)$ & $\left(0, \frac{2}{5}, \frac{1}{2}, \frac{1}{10}, 0\right)$ & 0.7 \\
\hline & & $\mathrm{Continues} \mathrm{next} \mathrm{page}$ \\
\hline
\end{tabular}

22

URL: http://mc.manuscriptcentral.com/lssp E-mail: comstat@univmail.cis.mcmaster.ca 


\begin{tabular}{|c|c|c|l|}
\hline $\mathbf{N}$ & $\mathbf{a}$ & $\mathbf{s}$ & $E(T)$ \\
\hline 60 & $(0,2,0,-2,1)$ & $\left(\frac{1}{5}, \frac{1}{5}, \frac{2}{5}, \frac{1}{5}, 0\right)$ & 0.7 \\
\hline $61-62$ & $(0,0,8,-11,4)$ & $\left(0, \frac{1}{5}, \frac{4}{5}, 0,0\right)$ & 0.7167 \\
\hline 63 & $(0,2,-1,1,-1)$ & $\left(0, \frac{1}{2}, \frac{3}{10}, \frac{1}{5}, 0\right)$ & 0.7167 \\
\hline $64-69$ & $(0,1,4,-6,2)$ & $\left(0, \frac{3}{10}, \frac{3}{5}, \frac{1}{10}, 0\right)$ & 0.7333 \\
\hline 70 & $(0,0,9,-13,5)$ & $\left(0, \frac{1}{10}, \frac{9}{10}, 0,0\right)$ & 0.75 \\
\hline $71-72$ & $(0,2,0,-1,0)$ & $\left(0, \frac{2}{5}, \frac{2}{5}, \frac{1}{5}, 0\right)$ & 0.75 \\
\hline $73-76$ & $(0,1,5,-8,3)$ & $\left(0, \frac{1}{5}, \frac{7}{10}, \frac{1}{10}, 0\right)$ & 0.7667 \\
\hline $77-82$ & $(0,2,1,-3,1)$ & $\left(0, \frac{3}{10}, \frac{1}{2}, \frac{1}{5}, 0\right)$ & 0.7833 \\
\hline 83 & $(0,0,10,-15,6)$ & $(0,0,1,0,0)$ & 0.7833 \\
\hline $84-85$ & $(0,1,6,-10,4)$ & $\left(0, \frac{1}{10}, \frac{4}{5}, \frac{1}{10}, 0\right)$ & 0.8 \\
\hline 86 & $(0,3,-3,2,-1)$ & $\left(0, \frac{2}{5}, \frac{3}{10}, \frac{3}{10}, 0\right)$ & 0.8 \\
\hline 87 & $(0,4,-6,4,-1)$ & $\left(\frac{1}{5}, \frac{1}{5}, \frac{1}{5}, \frac{2}{5}, 0\right)$ & 0.8 \\
\hline $88-94$ & $(0,2,2,-5,2)$ & $\left(0, \frac{1}{5}, \frac{3}{5}, \frac{1}{5}, 0\right)$ & 0.8167 \\
\hline 95 & $(0,3,-2,0,0)$ & $\left(0, \frac{3}{10}, \frac{2}{5}, \frac{3}{10}, 0\right)$ & 0.8333 \\
\hline 96 & $(0,1,7,-12,5)$ & $\left(0,0, \frac{9}{10}, \frac{1}{10}, 0\right)$ & 0.8333 \\
\hline $97-100$ & $(0,2,3,-7,3)$ & $\left(0, \frac{1}{10}, \frac{7}{10}, \frac{1}{5}, 0\right)$ & 0.85 \\
\hline 101 & $(0,4,-6,5,-2)$ & $\left(0, \frac{2}{5}, \frac{1}{5}, \frac{2}{5}, 0\right)$ & 0.85 \\
\hline $102-107$ & $(0,3,-1,-2,1)$ & $\left(0, \frac{1}{5}, \frac{1}{2}, \frac{3}{10}, 0\right)$ & 0.8667 \\
\hline $108-109$ & $(0,2,4,-9,4)$ & $\left(0,0, \frac{4}{5}, \frac{1}{5}, 0\right)$ & 0.8833 \\
\hline 110 & $(0,4,-5,3,-1)$ & $\left(0, \frac{3}{10}, \frac{3}{10}, \frac{2}{5}, 0\right)$ & 0.8833 \\
\hline $111-116$ & $(0,3,0,-4,2)$ & $\left(0, \frac{1}{10}, \frac{3}{5}, \frac{3}{10}, 0\right)$ & 0.9 \\
\hline $117-118$ & $(0,4,-4,1,0)$ & $\left(0, \frac{1}{5}, \frac{2}{5}, \frac{2}{5}, 0\right)$ & 0.9167 \\
\hline $119-122$ & $(0,3,1,-6,3)$ & $\left(0,0, \frac{7}{10}, \frac{3}{10}, 0\right)$ & 0.9333 \\
\hline $123-128$ & $(0,4,-3,-1,1)$ & $\left(0, \frac{1}{10}, \frac{1}{2}, \frac{2}{5}, 0\right)$ & 0.95 \\
\hline 129 & $(0,5,-7,4,-1)$ & $\left(0, \frac{1}{5}, \frac{3}{10}, \frac{1}{2}, 0\right)$ & 0.9667 \\
\hline $130-135$ & $(0,4,-2,-3,2)$ & $\left(0,0, \frac{3}{5}, \frac{2}{5}, 0\right)$ & 0.9833 \\
\hline $136-138$ & $(0,5,-6,2,0)$ & $\left(0, \frac{1}{10}, \frac{2}{5}, \frac{1}{2}, 0\right)$ & 1 \\
\hline $139-144$ & $(0,5,-5,0,1)$ & $\left(0,0, \frac{1}{2}, \frac{1}{2}, 0\right)$ & 1.0333 \\
\hline $145-146$ & $(0,6,-9,5,-1)$ & $\left(0, \frac{1}{10}, \frac{3}{10}, \frac{3}{5}, 0\right)$ & 1.05 \\
\hline 147 & $(1,0,0,1,-1)$ & $\left(0, \frac{2}{5}, \frac{1}{5}, \frac{1}{5}, \frac{1}{5}\right)$ & 1.05 \\
\hline $148-152$ & $(0,6,-8,3,0)$ & $\left(0,0, \frac{2}{5}, \frac{3}{5}, 0\right)$ & 1.0833 \\
\hline & & Continues next page \\
\hline
\end{tabular}




\begin{tabular}{|c|c|c|l|}
\hline $\mathrm{N}$ & $\mathbf{a}$ & $\mathbf{s}$ & $E(T)$ \\
\hline 153 & $(0,7,-12,8,-2)$ & $\left(0, \frac{1}{10}, \frac{1}{5}, \frac{7}{10}, 0\right)$ & 1.1 \\
\hline 154 & $(1,0,2,-3,1)$ & $\left(0, \frac{1}{5}, \frac{2}{5}, \frac{1}{5}, \frac{1}{5}\right)$ & 1.1167 \\
\hline $155-158$ & $(0,7,-11,6,-1)$ & $\left(0,0, \frac{3}{10}, \frac{7}{10}, 0\right)$ & 1.1333 \\
\hline 159 & $(1,0,3,-5,2)$ & $\left(0, \frac{1}{10}, \frac{1}{2}, \frac{1}{5}, \frac{1}{5}\right)$ & 1.15 \\
\hline $160-161$ & $(0,8,-14,9,-2)$ & $\left(0,0, \frac{1}{5}, \frac{4}{5}, 0\right)$ & 1.1833 \\
\hline 162 & $(1,0,4,-7,3)$ & $\left(0,0, \frac{3}{5}, \frac{1}{5}, \frac{1}{5}\right)$ & 1.1833 \\
\hline 163 & $(1,1,0,-2,1)$ & $\left(0, \frac{1}{10}, \frac{2}{5}, \frac{3}{10}, \frac{1}{5}\right)$ & 1.2 \\
\hline 164 & $(0,9,-17,12,-3)$ & $\left(0,0, \frac{1}{10}, \frac{9}{10}, 0\right)$ & 1.2333 \\
\hline 165 & $(1,1,1,-4,2)$ & $\left(0,0, \frac{1}{2}, \frac{3}{10}, \frac{1}{5}\right)$ & 1.2333 \\
\hline 166 & $(0,10,-20,15,-4)$ & $(0,0,0,1,0)$ & 1.2833 \\
\hline $167-168$ & $(1,2,-2,-1,1)$ & $\left(0,0, \frac{2}{5}, \frac{2}{5}, \frac{1}{5}\right)$ & 1.2833 \\
\hline 169 & $(1,3,-6,4,-1)$ & $\left(0, \frac{1}{10}, \frac{1}{5}, \frac{1}{2}, \frac{1}{5}\right)$ & 1.3 \\
\hline $170-171$ & $(1,3,-5,2,0)$ & $\left(0,0, \frac{3}{10}, \frac{1}{2}, \frac{1}{5}\right)$ & 1.3333 \\
\hline $172-173$ & $(1,4,-8,5,-1)$ & $\left(0,0, \frac{1}{5}, \frac{3}{5}, \frac{1}{5}\right)$ & 1.3833 \\
\hline 174 & $(1,5,-11,8,-2)$ & $\left(0,0, \frac{1}{10}, \frac{7}{10}, \frac{1}{5}\right)$ & 1.4333 \\
\hline 175 & $(1,6,-14,11,-3)$ & $\left(0,0,0, \frac{4}{5}, \frac{1}{5}\right)$ & 1.4833 \\
\hline 176 & $(2,-1,1,-2,1)$ & $\left(0,0, \frac{3}{10}, \frac{3}{10}, \frac{2}{5}\right)$ & 1.5333 \\
\hline 177 & $(2,1,-5,4,-1)$ & $\left(0,0, \frac{1}{10}, \frac{1}{2}, \frac{2}{5}\right)$ & 1.6333 \\
\hline 178 & $(2,2,-8,7,-2)$ & $\left(0,0,0, \frac{3}{5}, \frac{2}{5}\right)$ & 1.6833 \\
\hline 179 & $(3,-2,-2,3,-1)$ & $\left(0,0,0, \frac{2}{5}, \frac{3}{5}\right)$ & 1.8833 \\
\hline 180 & $(5,-10,10,-5,1)$ & $(0,0,0,0,1)$ & 2.2833 \\
\hline
\end{tabular}

